\title{
Development of Novel Controlled Release Gliclazide-Loaded poly $(\varepsilon-$ caprolactone) Microparticles: Effect of Polymer Blends
}

\author{
Nahla S Barakat ${ }^{1 *}$, Gamal Al-Shazli1,2 and Azza H Almedany ${ }^{3}$
}

${ }^{1}$ Department of Pharmaceutics, College of Pharmacy, King Saud University, P.O. Box 22452, Riyadh 11495, Saudi Arabia

${ }^{2}$ Department of Industrial Pharmacy, College of Pharmacy, Assuit University, Egypt

${ }^{3}$ Department of Pharmacology, College of Medicine, King Saud University, Saudi Arabia

\begin{abstract}
Gliclazide-loaded microparticles made with a polymeric blend were prepared by a solvent evaporation technique. Organic solutions of two polymers, poly (epsilon-caprolactone) (PCL) and Eudragit RS (E RS) or ethyl cellulose (EC), in different weight ratios, and $33.3 \%$ of GLZ were prepared and dropped into aqueous solution of poly vinyl alcohol, in different experimental conditions, achieving drug-loaded microparticles. The obtained microparticles were characterized in terms of yield of production, shape, size, surface properties, drug content, and in vitro drug release behavior. The physical state of the drugs and the polymer was determined by scanning electron microscopy (SEM), Fourier transform infra red and differential scanning calorimetry (DSC). Following the in vitro release studies microparticles made from blends of polymer, PCL/E RS or EC showed slower drug release than microparticles made from single PCL polymer. Surface morphology also revealed presence of porous and spherical structure of microparticles. Microparticles showing sustained release of GLZ were examined in rabbit and serum GLZ concentrations were calculated using HPLC method of assay.
\end{abstract}

Keywords: Gliclazide; Emulsion/solvent evaporation; Polycaprolactone; Eudragit RS; Ethyl cellulose; In vivo studies

\section{Introduction}

Biodegradable polymers have been the major focus of attempts to develop improved delivery systems for pharmaceutical research. The commonly studied biodegradable polymers for controlled drug delivery are the aliphatic polyesters; poly (lactide), poly (glycolide), poly- $\varepsilon$ caprolactone (PCL) and their copolymers [1]. The successful use of these polymers in pharmaceutical applications has naturally led to the evaluation of other aliphatic polyesters such as poly ( $\varepsilon$-caprolactone) (PCL), a biocompatible semi-crystalline polymer with a very low glass transition temperature [2]. The interest of PCL has been recently highlighted as platform for oral delivery of low molecular weight drugs [3]. This polymer has been also studied as a carrier for oral vaccines $[4,5]$, and also to entrap non-steroideal anti-inflammatory drugs [6] and estrogens [7]. Poly ( $\varepsilon$-caprolactone) has also been blended with alphatic polyesters $[8,9]$ to obtain microparticles of different biodegradability for the release of different drugs. The advantages of PCL include its high permeability to small drug molecules, their failure to generate an acidic environment during degradation as compared to polylactides and glycolides, an exceptional ability to form blends with other polymers and degradation of PCL homopolymer being slow as compared to PLGA and polyglycolic acid-co-lactic acid making it more suitable for long term delivery systems extending to a period of more than one year [10]. Various categories of drugs have been encapsulated in PCL microparticles for their effective delivery. Microparticles can be prepared either by PCL alone, or by using copolymers with PCL or PCL blends in order to obtain the desired release characteristics. The fabrication of PCL microparticles from blends of PCL and polyethylene glycols has also been studied [11]. Various techniques, mainly based on a one step emulsification process, have been used to prepare microparticulate sustained drug delivery systems. Selection of the microencapsulation technique is primarily determined by the solubility of the drug and the polymer in various solvents systems [12].

Gliclazide is a short-acting sulfonylurea oral hypoglycemic agent widely used for the treatment of non-insulin-dependent diabetes mellitus (NIDDM) [13]. In general, rapid gastrointestinal (GI) absorption is required for oral hypoglycemic drugs, to prevent a sudden increase in blood glucose level after food intake in patients with NIDDM. However, the absorption rate of gliclazide from the gastrointestinal tract is slow and variable. A slow absorption of a drug usually originates from either poor dissolution of the drug from the formulation or poor permeability of the drug across the GI membrane [14]. The dose of gliclazide is $80 \mathrm{mg}$ and could be increased to $380 \mathrm{mg}$ daily, highlighting a need for the development of a sustained-release, patient-compliant formulation of gliclazide [15].

The objectives of our work are firstly to entrap Gliclazide within PCL- as a single polymer and as a blend of polymer with Eudragit RS/ or ethyl cellulose- into microparticles prepared by the $\mathrm{o} / \mathrm{w}$ emulsion/solvent evaporation method and secondly to characterize the formulation in terms of a drug loading and release, morphology, size and physical state of both the drugs and the polymer. The best formulation providing sustained drug release was selected for determination of the pharmacokinetics properties of GLZ in rabbit after oral administration (Part II).

\section{Materials and Methods}

\section{Materials}

Gliclazide (GLZ) was received as a gift sample from AlQassem

*Corresponding author: Nahla S. Barakat, Department of Pharmaceutics, College of Pharmacy, King Saud University, P.O. Box-22452, Riyadh-11495, Saudi Arabia Tel: +966502963114; Fax: +96614092517, E-mail: nsybarakat@yahoo.com

Received January 14, 2012; Accepted March 15, 2012; Published March 17, 2012

Citation: Barakat NS, Al-Shazli G, Almedany AH (2012) Development of Nove Controlled Release Gliclazide-Loaded poly(E-caprolactone) Microparticles: Effect of Polymer Blends. Pharm Anal Acta 3:150. doi:10.4172/2153-2435.1000150

Copyright: (c) 2012 Barakat NS, et al. This is an open-access article distributed under the terms of the Creative Commons Attribution License, which permits unrestricted use, distribution, and reproduction in any medium, provided the original author and source are credited. 
Citation: Barakat NS, Al-Shazli G, Almedany AH (2012) Development of Novel Controlled Release Gliclazide-Loaded poly( $\varepsilon$-caprolactone) Microparticles: Effect of Polymer Blends. Pharm Anal Acta 3:150. doi:10.4172/2153-2435.1000150

Page 2 of 9

pharmaceutical Ltd (Saudi Arabia). Poly ( $\varepsilon$-caprolactone) (PCL) $(65,000$ MW) was obtained from Sigma-Aldrich, Switzerland). Eudragit ${ }^{\circledR}$ RS was supplied by Röhm GmbH (Darmstadt, Germany). Ethyl cellulose, 20 Premium was supplied by Colorcon (UK). Dichloromethane was purchased from Sigma-Aldrich, (USA). Analytical-grade dichloromethane and HPLC grade acetonitrile and methanol were supplied by Carlo Erba. Poly vinyl alcohol (PVA) (87-90\% hydrolyzed, MW 13,000-23,000) were obtained from Aldrich (USA). All other reagents were analytical reagents grade and used as supplied.

\section{Method}

Preparation of microparticles: Microparticles of GLZ-loaded PCL were prepared using a solvent evaporation method as previously described [16,17]. Polymer solutions containing PCL and GLZ and $50 \mathrm{mg}$ glyceryl monostearate as dispersing agent and plasticizer per $10 \mathrm{ml}$ solvent, with or without additive polymers were made up in dichloromethane to a final concentration of $10 \%(\mathrm{w} / \mathrm{v})$. Ten milliliters of polymer solution were then pipetted into $100 \mathrm{~mL}$ of $0.5-1.5 \% \mathrm{w} / \mathrm{v}$ PVA stirring at $600 \mathrm{rpm}$ (Ika, Yellow line, UK), and then $100 \mathrm{ml}$ of distilled water were added in order to favor the diffusion of the organic solvent into the external aqueous phase and promote microsphere hardening. After $2 \mathrm{~h}$, the microparticles were collected by centrifugation (Hettich Zentrifugen, Universal 16R), washed three times with distilled water and under vacuum at room temperature. Formulations of microparticles are given in table 1. For each formulation, at least three independent batches were prepared. Unloaded microparticles were prepared, following the same processes. To calculate the yield of each preparation, the weight of the recovered dry particles was recorded. The final product was then sieved using a vibrating shaker (AS200 basic, Restch, Germany) through $125 \mu \mathrm{m}$ and $500 \mu \mathrm{m}$ sieves (Restch, Germany) - the fraction between the sieves was designated the useful fraction. Larger microparticles are expected to have better flow properties compared to smaller microparticles, which could be advantageous if the microparticles are compressed into tablets. Microparticles larger than $500 \mu \mathrm{m}$ are expected to be agglomerates.

\section{Characterization of GLZ-loaded microparticles}

Morphology of GLZ-loaded microparticles: The size distributions of GLZ-loaded microparticles were examined by with a laser diffraction particle size analyzer (SALD-2101 Shimadzu, Japan). The particle size distribution and mean particle size diameter were automatically calculated using the software provided. The size distribution was evaluated with the span value defined as follows:

$($ Polydispersity $)$ Span $=(\mathrm{D} 90 \%-\mathrm{D} 10 \%) / \mathrm{D} 50 \%$
Where, $\mathrm{DN} \%(\mathrm{~N}=10,50,90)$ means the volume percentage of microparticles with diameters up to $\mathrm{DN} \%$. The smaller span value indicates the narrower particle size distribution.

Determination of dispersing media viscosity: Viscosities of different dispersed phase of formulations were determined with rotational viscometery (Brookfield Model LDV-II, USA) by using RV3 spindle at the rate of $50 \mathrm{rpm}$ and $25^{\circ} \mathrm{C}$.

Drug content and incorporation efficiency: Fifty milligrams of GLZ microparticles were accurately weighed, grinded and dissolved in $100 \mathrm{ml}$ of phosphate buffer $\mathrm{pH} 7.4$; the solution was stirred by a magnetic stirrer for $4 \mathrm{hr}$. Then $1 \mathrm{ml}$ of the solution was transferred to $50 \mathrm{ml}$ volumetric flask and diluted with phosphate buffer to the volume. An absorbance of the solution was measured with UV/Vis spectrophotometer (Ultrospec 2100, UK) at 228 wavelength $\mathrm{nm}$, using phosphate buffer as a blank. An amount of GLZ was calculated from the calibration curve. The analysis was performed in triplicate.

The percentage of the production yield of the microparticles, percentage of drug content, and percentage of drug entrapment were calculated from the following equations [18].

$\%$ Production yield $=\frac{\text { Total weight of the microparticles }}{\text { Total weight of GLZ polymers }(\mathrm{s})} \times 100$

$\%$ Drug content $=\frac{\text { Calculated amount of GLZ }}{\text { Total weight of microparticles }} \times 100$

$\%$ Drug entrapment $=\frac{\% \text { Drug content }}{\% \text { Theoretical content }} \times 100$

Differential scanning calorimetric (DSC) analysis: Differential scanning calorimetry thermograms (DSC) of Gliclazide, Polycaprolactone, Eudragit RS, ethyl cellulose, their physical mixture and microparticles formulations were performed in a DSC-50 cell (Shimadzu). Samples (2-4 mg) were placed in sealed aluminum pans and heated at $10^{\circ} \mathrm{C} / \mathrm{min}$ under a nitrogen atmosphere (flow rate $20 \mathrm{ml} /$ min) in the $30-400^{\circ} \mathrm{C}$ range. An empty aluminum pan was used as a reference. The equipment was calibrated for baseline and temperature with indium metal. The sample was hermetically sealed in an aluminum pan and run from 10 to $200^{\circ} \mathrm{C}$ at a scanning rate of $10^{\circ} \mathrm{C} / \mathrm{min}$.

Fourier transform infrared spectral (FTIR) studies: FTIR spectra of pure components, their physical mixture and microparticles were recorded using a attenuated total reflectance FTIR instrument (Spectrum RXI FT-IR, Perkin Elmer, USA) using KBr disk technique,

\begin{tabular}{|c|c|c|c|c|c|c|c|}
\hline Formula code & PCL (g) & $\begin{array}{l}\text { Eudragit RS or } \\
\qquad \mathrm{EC}(\mathrm{g})\end{array}$ & $\begin{array}{c}\text { Encapsulation } \\
\text { efficiency }(\%) \pm S D\end{array}$ & Production yield $(\%) \pm S D$ & Mean diameter $(\mu \mathrm{m}) \pm S D$ & Polydi-spersity & $\begin{array}{l}\text { Viscosities of dispersion } \\
\text { medium (mPa s) }\end{array}$ \\
\hline $\mathrm{F} 1$ & 1.0 & 0.00 & $90.72 \pm 1.78$ & $92.34 \pm 3.21$ & $225 \pm 1.82$ & 0.436 & 14.0 \\
\hline $\mathrm{F} 2$ & 0.2 & 0.8 & $92.87 \pm 1.09$ & $90.38 \pm 4.10$ & $318 \pm 1.72$ & 0.094 & 17.6 \\
\hline $\mathrm{F} 3$ & 0.5 & 0.5 & $89.32 \pm 2.72$ & $88.92 \pm 2.81$ & $312 \pm 2.80$ & 0.340 & 15.8 \\
\hline $\mathrm{F} 4$ & 0.7 & 0.3 & $92.36 \pm 3.84$ & $94.31 \pm 4.82$ & $305 \pm 1.35$ & 0.610 & 15.2 \\
\hline F5 & 0.8 & 0.2 & $94.59 \pm 2.63$ & $89.43 \pm 5.71$ & $280 \pm 2.09$ & 0.316 & 14.7 \\
\hline F6 & 0.2 & 0.8 & $91.67 \pm 3.98$ & $88.87 \pm 5.44$ & $375 \pm 1.93$ & 0.071 & 20.0 \\
\hline $\mathrm{F} 7$ & 0.5 & 0.5 & $93.75 \pm 4.65$ & $89.32 \pm 3.98$ & $355 \pm 3.85$ & 0.078 & 18.3 \\
\hline F8 & 0.7 & 0.3 & $90.27 \pm 4.44$ & $91.38 \pm 2.95$ & $330 \pm 2.84$ & 0.056 & 16.3 \\
\hline F9 & 0.8 & 0.2 & $94.28 \pm 1.62$ & $96.32 \pm 3.76$ & $270 \pm 1.65$ & 0.115 & 15.4 \\
\hline
\end{tabular}

F2-F5 microparticles composed of PCL/RS blend

F6-F9 microparticles composed of PCL/EC blend

F1-F9 GLZ content is $33.3 \%$ (1:2, GLZ: polymer)

Table 1: Quantitative analysis of the GLZ-loaded Polycaprolactone microparticles $(n=3)$. 
and IR measurements were performed in transmission in the scanning range of $4000-400 \mathrm{~cm}^{-1}$ at ambient temperature. Similar drug: polymer proportions to those analytically determined in the microparticles were used for preparing the different physical mixtures that were used as control for thermal analysis and IR studies.

Scanning electron microscopic (SEM) studies: The surface morphology of GLZ microparticles were examined by means of scanning electron microscope (SEM, JSM-5300 LV, JEOL, Tokyo, Japan). Electron micrographs of GLZ microparticles were obtained using a scanning electron microscope operating at $25 \mathrm{kV}$. The samples were mounted on a glass stub with double-sided adhesive tape and coated under vacuum with gold in an argon atmosphere prior to observation. Micrographs with different magnifications were recorded to study the morphological and surface characteristics of microparticles.

In vitro drug release : A weighed sample of blank unloaded and drug- loaded microparticles (equivalent to $80 \mathrm{mg} \mathrm{GLZ)} \mathrm{were} \mathrm{suspended}$ in $900 \mathrm{ml} 0.1 \mathrm{~N}$ hydrochloric acid solution at $\mathrm{pH} 1.2$ for the first $2 \mathrm{~h}$, and then replaced with the phosphate buffer solution, $\mathrm{pH} 6.8$ for further $6 \mathrm{~h}$. The dissolution medium was stirred at $100 \mathrm{rpm}$. Sink conditions were maintained throughout the assay period. All the experiments were carried out at $37 \pm 0.5^{\circ} \mathrm{C}$ for $24 \mathrm{~h}$. Aliquots of the dissolution medium $(2 \mathrm{ml})$ were withdrawn at predetermined time points and filtered through Millipore, $0.45 \mu \mathrm{m}$ filter. Amount of dissolved drug was determined spectrophotometrically at $228 \mathrm{~nm}$ against polymer carrier as blank. The dissolution medium was maintained at a constant volume by replacing the samples with fresh dissolution medium. The measurements were performed in triplicate and average values were considered for data analysis.

Mathematical models of release kinetics: Kinetics of GLZ released from the prepared solid dispersions, were examined based on the magnitude of correlation coefficients obtained after application of zero order, first order, Korsemeyer-Peppas and Higuchi diffusion models employing the following set of equations:

\section{Zero-order model:}

$\mathrm{M}_{0}-\mathrm{M}_{\mathrm{t}}=\mathrm{k}_{0} \mathrm{t}$

First-order model:

$\operatorname{Ln} \mathrm{M}_{0} / \mathrm{M}_{\mathrm{t}}=\mathrm{k}_{1} \mathrm{t}$

Higuchi model:

$\mathrm{M}_{\mathrm{t}}=\mathrm{kt}^{1 / 2}$

Korsemeyer-Peppas model:

$\mathrm{M}_{\mathrm{t}} / \mathrm{M}_{\infty}=\mathrm{kt}^{\mathrm{n}}$

where $M_{0}, M_{t}$ and $M_{\infty}$ correspond to the drug amount taken at time equal to zero, dissolved at a particular time, $t$, and at infinite time, respectively. The terms $M_{0}$ and $M_{t}$ refer to the weight of the drug taken initially and at time t. Various other terms viz. $\mathrm{k}, \mathrm{k}_{0}, \mathrm{k}_{1}$ and $\mathrm{k}$ refer to the release kinetic constants obtained from the linear curves of Korsemeyer-Peppas, zero-order, first-order, and Higuchi model, respectively [19].

In vivo studies: Male New Zealand white rabbits weighing 2.0-2.5 $\mathrm{kg}$ were used for the animal model. All investigations were performed according to the European Community guidelines for animal experimentation. Experimental design and treatment of animals were approved by the Animal Care Committee of King Saud University, School of Medicine. The animals were housed in polypropylene cages, 6 animals per cage with free access to standard laboratory diet and water. They were kept at $25^{\circ} \mathrm{C}$ and $55 \%$ relative humidity with a 12 -h light/ dark cycle. The suspension of GLZ-loaded microparticle (F2, F7) in 2\% sodium carboxymethyl cellulose (CMC), GLZ solution was prepared by dissolving GLZ in a few drops of $0.1 \mathrm{~N} \mathrm{NaOH}$ then made up to the volume with distilled water. After light anaesthetization with ether all the drugs were administered to the respective groups (each 6 rabbits)

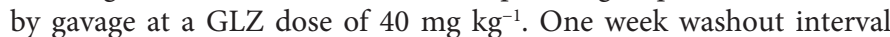
was allowed between the two phases of the study. The experiment were conducted as per a crossover randomized design $(n=6)$. The products were administered orally at morning following overnight fasting. No food or liquid other than water was given during the experimental period. Blood samples $(0.5 \mathrm{~mL})$ were collected from the marginal ear vein of each rabbit at $0,0.50,1,1.5,2,3,4,6,8,12,24$ and $48 \mathrm{~h}$ after administration separately. Blood samples were placed into heparinized tubes and separated immediately by centrifugation; the plasma obtained was stored at $-20^{\circ} \mathrm{C}$ until analysis. The in vivo availability of Formulae F2 and F7 compared to GLZ solution was assessed by comparing the plasma concentration-time profile of the two products. The pharmacokinetic parameters derived from these profiles, such as maximum GLZ plasma concentration $\left(\mathrm{C}_{\max }\right)$, the time needed to reach this peak concentration $\left(\mathrm{T}_{\mathrm{mo}}\right)$, area under plasma concentration-time curve (AUC) for 24 hours and for infinity were also assessed applying the following equation:

$$
\mathrm{AUC}_{0-\infty}=\mathrm{AUC}_{0-\mathrm{t}}+\mathrm{Ct} / \mathrm{Ke}
$$

Where, $\mathrm{k}_{\mathrm{el}}$ (the elimination rate constant), can be estimated by fitting the logarithm of the concentration versus time to a straight line over the observed exponential decline.

HPLC condition: GLZ plasma concentrations were determined by HPLC analysis as determined by a validated reverse-phase HPLC method [20]. The HPLC apparatus (Shimadzu VP series) equipped with System controller (SCL-10 AVP, Shimadzu); UVVis Spectrophotometer detector (SPD-10 AVP, Shimadzu, Japan), a Rheodyne sample injector (Rheodyne, USA) with $50 \mu$ sample loop and Bondapak $\mathrm{C}_{18}(4.6 \mathrm{~mm}$ (id) $\times 150 \mathrm{~mm}$ and $5-\mu \mathrm{m}$ particle size $)$ column. The mobile phase consisted of methanol and phosphate buffer $(70: 30, \mathrm{v} / \mathrm{v}) \mathrm{pH} 4.0,(\mathrm{pH}$ was adjusted with orthophosphoric acid) at a flow rate of $1.5 \mathrm{ml} / \mathrm{min}$ that led to a retention time of 3.5 minutes when detection was carried out at $228 \mathrm{~nm}$.

Preparation of standard and sample solutions: A stock solution of GLZ was prepared at a concentration of $10 \mu \mathrm{g} / \mathrm{mL}$ by dissolving the appropriate amount of the reference standards in methanol. The standard solutions were prepared from the stock by the appropriate dilution. These solutions were stable for 3 week when stored at $2-8^{\circ} \mathrm{C}$.

Analysis of GLZ in plasma: The plasma gliclazide concentrations were determined by HPLC method [20] with some modification. One $\mathrm{mL}$ of plasma sample was placed into a centrifuge tube and $10 \mu \mathrm{L}$ of internal standard (Glipizide, $50 \mu \mathrm{g} / \mathrm{mL}$ ). The sample was extracted with $6 \mathrm{~mL}$ of dichloromethane under vigorous shaking at room temperature for $30 \mathrm{~s}$. The tubes were shaken on a rotator for $10 \mathrm{~min}$.

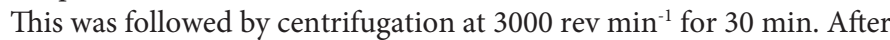
centrifugation, the organic phase was transferred into $\mathrm{V}$-tubes and evaporated to dryness under a stream of nitrogen at $45^{\circ} \mathrm{C}$. The dried extract was reconstituted with $200 \mu \mathrm{L}$ of mobile phase, vortex-mixed and transferred to a clean $1.5 \mathrm{~mL}$ eppendorf tube, and centrifuged for 2 minutes at $12,000 \mathrm{rev} \mathrm{min}^{-1}$ in a microcentrifuge. Then, $100 \mu \mathrm{L}$ of this solution was injected into the HPLC system.

Calibration curves were prepared by linear regression analysis of 
the plot of the peak area against the concentration of GLZ covering the range of $0.05-4.0 \mu \mathrm{gmL}^{-1}$. The concentration of plasma samples was determined from the area of the chromatographic peak using the calibration graph. The limit of detection was $30 \mathrm{ng} \mathrm{mL} \mathrm{m}^{-1}$. The pharmacokinetic parameters of gliclazide were determined on subjecting the concentration-time data to non-compartmental analysis using WinNonlin (Pharsight, Mountain View, CA, version, 2.0) software. The analytical performance parameters such as specificity, linearity, range, precision, accuracy and limit of detection and limit of quantification were validated according to International Conference on Harmonization ICH guidelines [21].

Statistical analysis: The results are expressed as mean \pm standard deviation (S.D.). The results were analyzed by a student's t-test using GraphPad InStat Software (Version: 3.0). The statistics were assessed using the Kruskal-Wallis test. Individual differences between the three GLZ formulations after oral administration were determined using a nonparametric Dunn's multiple comparison tests and a value of $P<$ 0.05 was considered statistically significant. Results are presented as mean values $\pm \mathrm{SD}$.

\section{Results and Discussion}

\section{Preparation and characterization of microparticles}

Microparticles were prepared by the simple emulsion-solvent evaporation technique, widely employed to produce particles from different polymers [22]. The optimized morphology of the microparticles was obtained using a polymer concentration of $10 \%$ $\mathrm{w} / \mathrm{v}$ and a PVA concentration in the aqueous phase of $1.5 \% \mathrm{w} / \mathrm{v}$. It was necessary to add PVA as dispersing agent to the continuous aqueous phase to reduce the interfacial tension and to stabilize emulsion droplets to such an extent as to limit collapse before polymer precipitation and microsphere hardening [23]. Concentrations of PVA below 1.5\% (w/v) were unable to prevent the coagulation of microparticles and, thereby, the subsequent formation of large aggregates. Gleceryl monostearate was used as a plasticizer in the microparticles formulations and incorporated in the inner phase to improve flexibility of the polymer chains [24].

The methodology that uses the dissolution of both drug and polymer in the solvent system provides a homogeneous distribution of the drug and the polymer into the microdroplet during the solvent removal in the solvent evaporation process.

\section{Production yield and encapsulation efficiency}

The production yield and encapsulation efficiency of GLZ-loaded microparticles are shown in table 1. The total percentage yields of GLZ-microparticles prepared using single PCL polymer or polymer blends are ranged from $88.43-95.72 \%$. Furthermore, the efficiency of encapsulation of GLZ-loaded PCL microparticles was determined by HPLC. Neither any peak for a biodegradable polymer nor any alteration of the chromatographic pattern of GLZ was observed, indicating that the selected parameters for the microencapsulating process did not affect the stability of the drug. Good levels of drug-loading efficiency were achieved for all microparticle systems, with values varying from 87.8 to $92.9 \%$, depending on the drug: polymer proportions. The results demonstrating the high level of GLZ entrapped into PCL microparticles are shown in table 1 .

\section{Particle size analysis of the microparticles}

Mean particle size of microparticles is shown in table 1 . The mean diameters (d4.3) ranged from 230 to $374 \mu \mathrm{m}$ for all formulations. The mean particle size was not affected by the polymer type and the ratio of the mixture of polymer for all formulations, $P>0.05$ among the different formulations. This feature can be explained by the low viscosity and the low concentrations of the drug/polymer mixture of the dropped organic solution [25]. The particle size slightly decreased according to the increase of the PCL concentrations for the GLZloaded formulations. Furthermore, the SPAN values calculated for all the samples in this study were lower than 2 , indicating that the particle size distribution is adequately narrow. Viscosities of the dispersion phase also play a role in determining particle size of the formulations. Replacing Eudragit RS and ethyl cellulose in place of PCL leads to increase in viscosity of the medium (Table 1). Some researchers pointed out that particle sizes are proportional with dispersed phase viscosities [26]. When dispersed phase with higher viscosity was poured into the dispersion medium, bigger droplets were formed and mean particle size increased. Formulation containing ethyl cellulose showed higher viscosity than those with Eudragit RS.

\section{Thermal analysis of the microparticles}

The crystallinity and amorphicity of individual components and microparticles formulations were further tested by DSC (Figure 1). The melting temperatures $(\mathrm{Tm})$ obtained for the raw materials were $169^{\circ} \mathrm{C}$ for GLZ and $63.3^{\circ} \mathrm{C}$ for PCL that further confirmed the crystallinity. Ethyl cellulose showed an exothermic peak at $198^{\circ} \mathrm{C}$. The $T \mathrm{~m}$ values of PCL polymer in the physical mixtures, prepared at the proportions of (PCL: RS) 7:3 and 1:1 (w/w), were $61.9,61.9^{\circ} \mathrm{C}$. The Tm values of the mixtures were shifted to lower values after loading GLZ. The physical
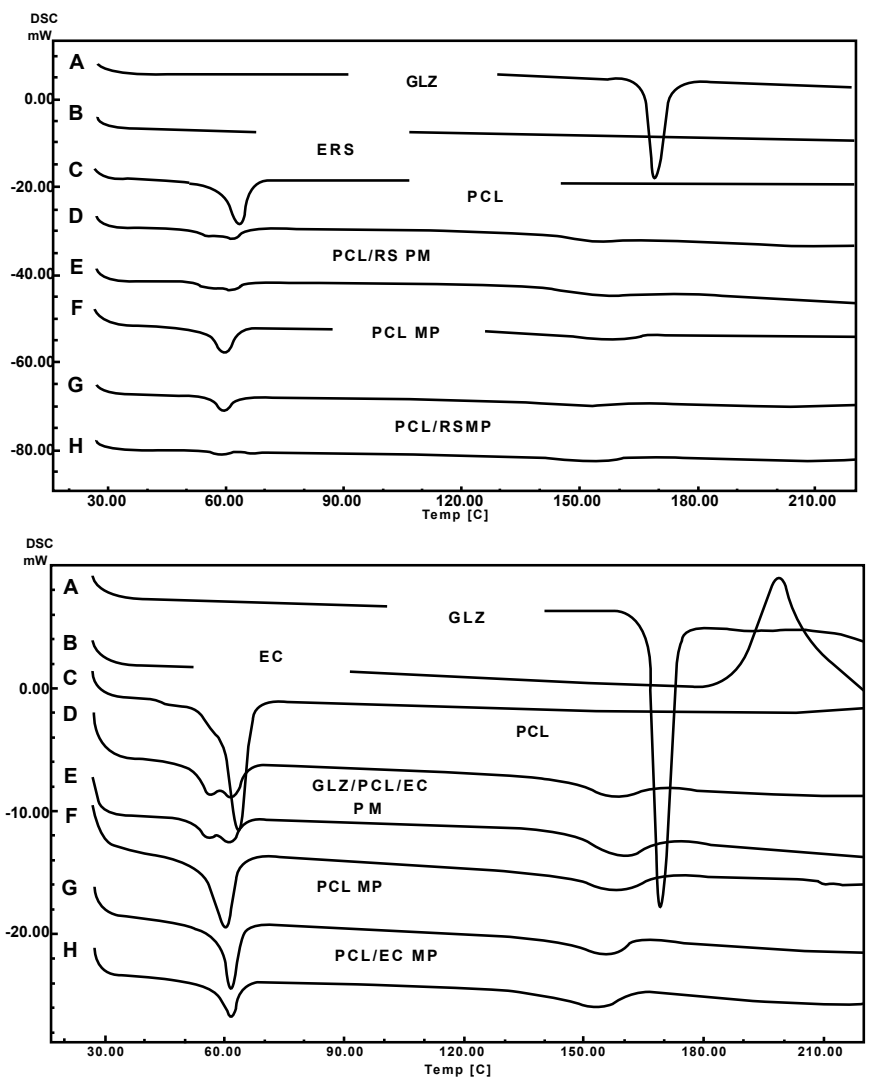

Figure 1: DSC thermogram of GLZ, CL, E RS, EC, and GLZ/polymer blend physical mixture, and GLZ-loaded microparticles. 
Citation: Barakat NS, Al-Shazli G, Almedany AH (2012) Development of Novel Controlled Release Gliclazide-Loaded poly( $\varepsilon$-caprolactone) Microparticles: Effect of Polymer Blends. Pharm Anal Acta 3:150. doi:10.4172/2153-2435.1000150
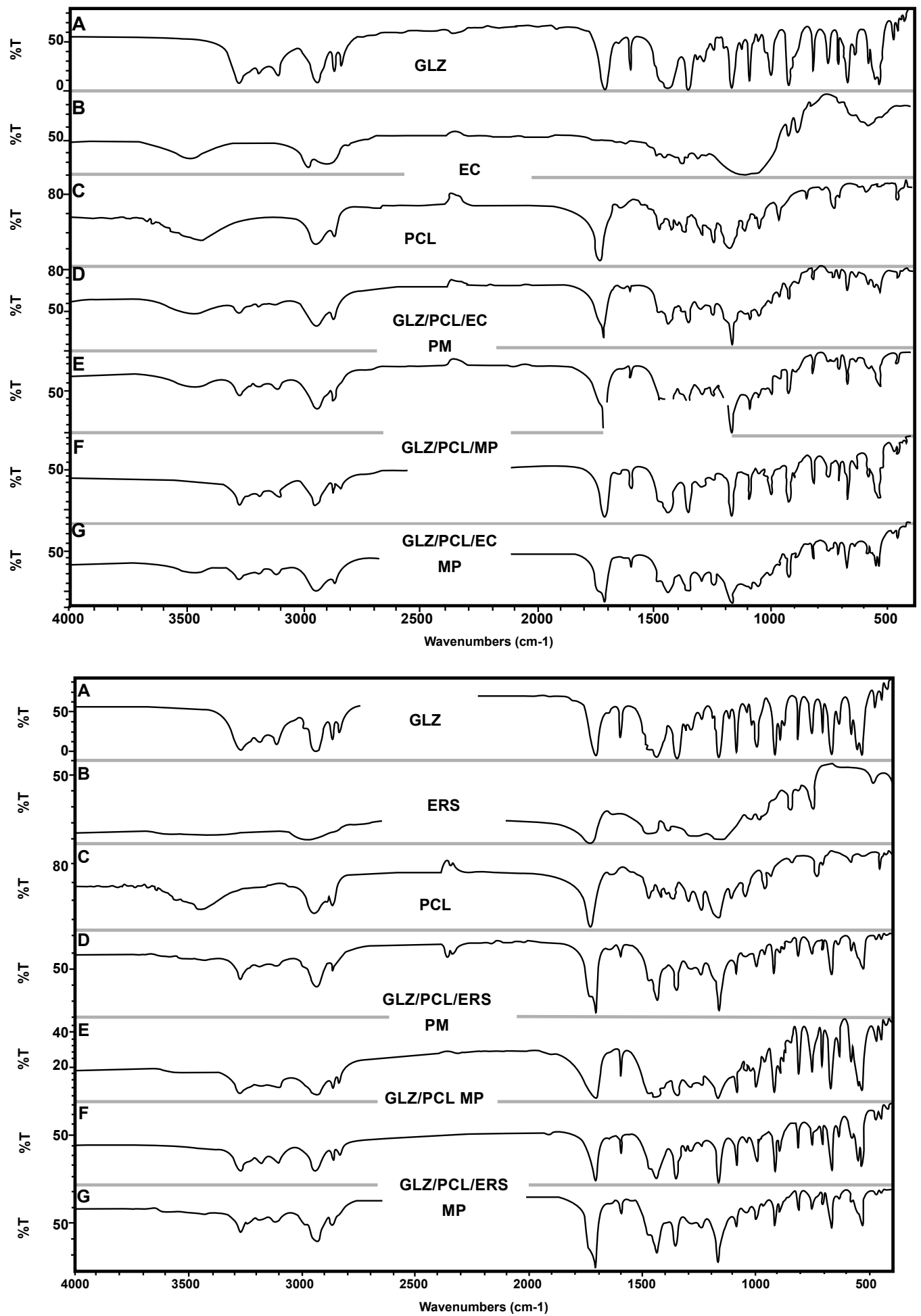

B

Figure 2: FTIR spectra of GLZ, individual polymer PCL, Eudragit RS, ethylcellulose, physical mixture and GLZ-loaded microparticles, Formula F3 \& F7.

mixtures showed an endothermic peak at $158.8^{\circ} \mathrm{C}$ which corresponded to the GLZ melting point. Similarly, the microparticles formulations showed characteristic shifted endothermic peaks of GLZ at $155.7^{\circ} \mathrm{C}$ and $156.8^{\circ} \mathrm{C}$ for PCL/EC and PCL/RS formulations which indicated that the drug existed in the crystalline forms in these formulations. The
Tm values of PCL in the microparticles were $61.7^{\circ} \mathrm{C}$ and $61.5^{\circ} \mathrm{C}$ for PCL: EC and PCL: RS, respectively.

\section{FTIR spectral studies}

FTIR spectra were employed to confirm the compatibility of GLZ 
Citation: Barakat NS, Al-Shazli G, Almedany AH (2012) Development of Novel Controlled Release Gliclazide-Loaded poly( $\varepsilon$-caprolactone) Microparticles: Effect of Polymer Blends. Pharm Anal Acta 3:150. doi:10.4172/2153-2435.1000150

Page 6 of 9

A

a

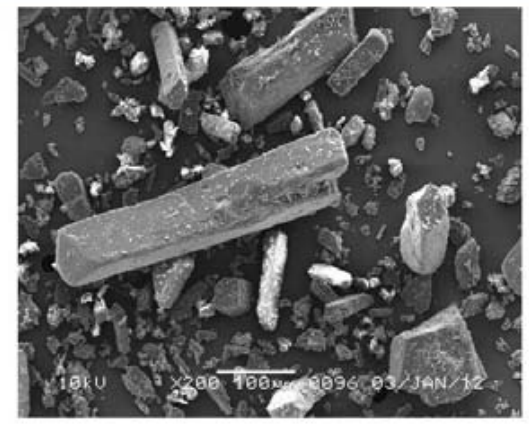

C

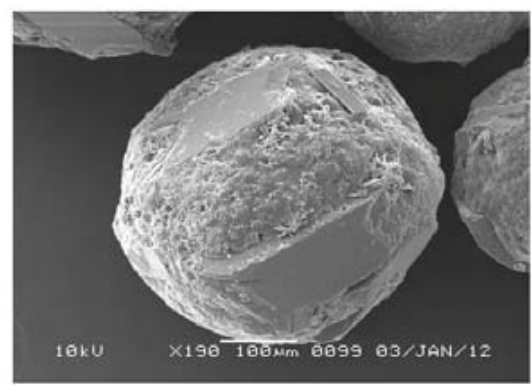

B

a

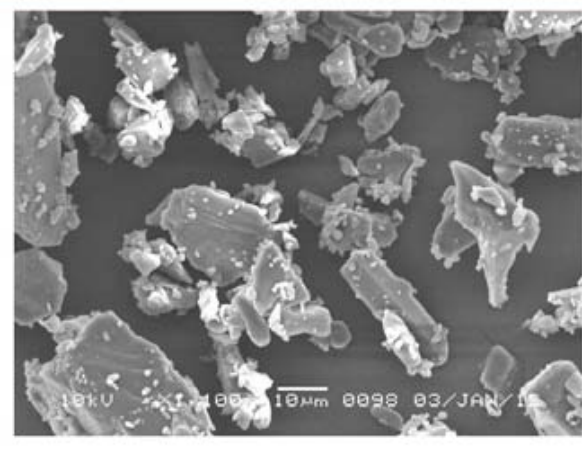

C

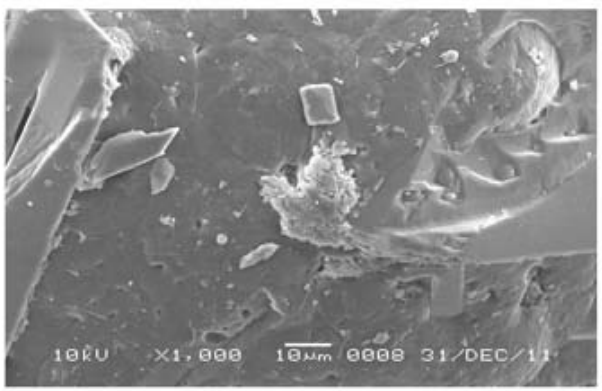

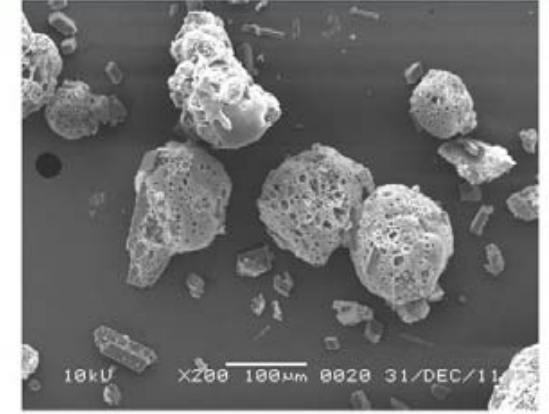

b

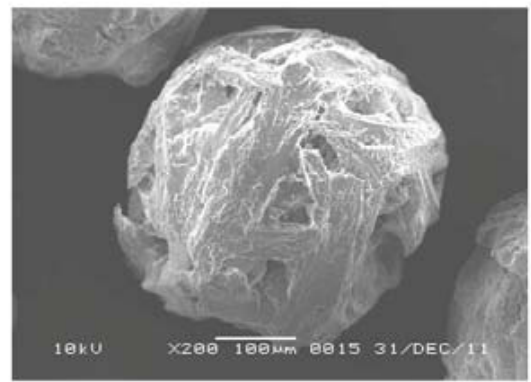

d

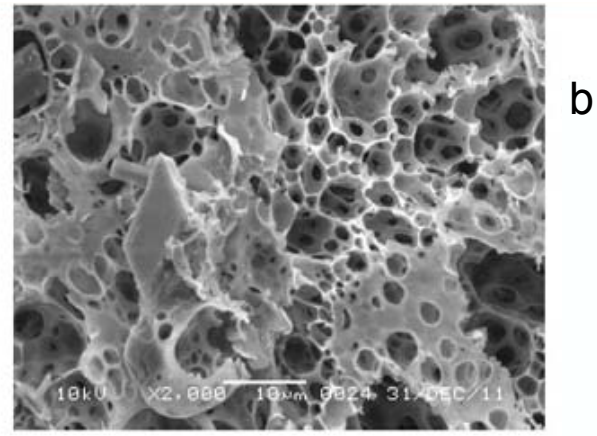

b

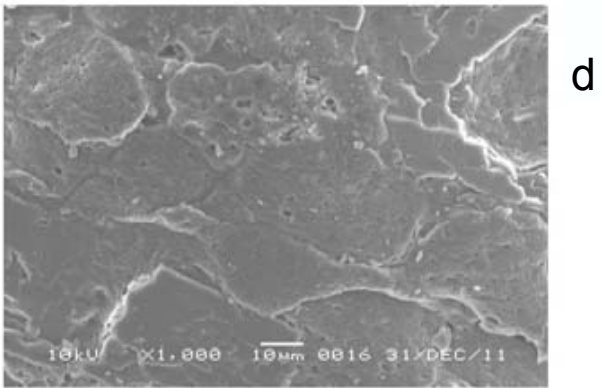

Figure 3: Scanning electron micrographs of PCL and PCL/polymer blend microparticles loaded with GLZ: (a) GLZ; (b) PCL alone; (c) GLZ-loaded PCL/ RS 1:1(w/w) microparticles; (d) GLZ-loaded PCL/EC 1:1 (w/w) microparticles. (A) External morphology; (B) surface morphology.

with various polymers used to prepare the microparticles. The IR spectrum of the resulting GLZ microparticles is shown in figure 2. The FT-IR of gliclazide was found consistent and unaffected by the various polymers. The following peaks are seen presented no shift and no change in frequency: the peaks of $\mathrm{NH}$ stretching $\left(3.274 \mathrm{~cm}^{-1}\right),-\mathrm{CH}$ stretching $\left(3.113 \mathrm{~cm}^{-1}\right), \mathrm{O}=\mathrm{C}\left(1.705 \mathrm{~cm}^{-1}\right), \mathrm{C}=\mathrm{C}$ aromatic $\left(1.596 \mathrm{~cm}^{-1}\right)$ C-H deformation $\left(1.467-1.430 \mathrm{~cm}^{-1} 1\right) \mathrm{SO}_{2}-\mathrm{NH}\left(1.352 \mathrm{~cm}^{-1}\right)$. Similar peaks were seen in GLZ-loaded microparticles (Figure 2). The broad and strong band ranging from $3.200-3.600 \mathrm{~cm}^{-1}$ may be due to the overlapping of $-\mathrm{OH}$ and $-\mathrm{NH}$ stretching vibration, consistent with the peak at $1.155 \mathrm{~cm}^{-1}$ assigned to $\mathrm{C}-\mathrm{N}$ stretching vibration [27]. In short, the microparticles prepared with different polymer blends had significant characters of GLZ in the FTIR spectrum, suggesting there were no reactions between the GLZ and the polymers used.

\section{Scanning electron microscopic studies}

The surface morphology of microparticles was observed by scanning electron microscopy and representative micrographs are 
Citation: Barakat NS, Al-Shazli G, Almedany AH (2012) Development of Novel Controlled Release Gliclazide-Loaded poly( $\varepsilon$-caprolactone) Microparticles: Effect of Polymer Blends. Pharm Anal Acta 3:150. doi:10.4172/2153-2435.1000150

shown in figure 3. The solvent elimination method accompanied by important shrinkage determines the microparticle morphology and its encapsulation. Almost spherical shapes with rough surface of particles were obtained. In addition, no significant fusion among particles was observed. Surface morphology also revealed presence of porous and spherical structure of microparticles (Figure 3). Moreover, morphology of microparticles revealed that degree of porosity of microparticles was dependent on the composition of polycaprolactone present in the microparticles. The photomicrographs also showed the presence of loose crystals on the surface of a few microparticles. The appearance of microparticles changed dramatically as the polycaprolactone content in the microparticles matrix increased. Decrease the content of polycaprolactone leads to loss of porosity. There were less pores appeared in microparticles with high content of Eudragit RS or ethyl cellulose.

\section{In vitro release studies}

It is well known that microparticles prepared by single emulsion evaporation method present initial burst release due to surface located encapsulated substance. Usually emulsion formation is used for the encapsulation of oil soluble substances. Due to its hydrophobic character, the encapsulated substance will agglomerate towards the microparticle surface during the intense solvent elimination. This enriched layer on the particle surface will contribute to the initial burst release. The pores present on the capsule wall will decisively contribute to the initial burst release [28]. In vitro dissolution studies were performed in $0.1 \mathrm{~N} \mathrm{HCl}$ for 2 hours and followed by phosphate buffer $\mathrm{pH} 6.8$ for 6 hours to simulate the gastro intestinal tract (GIT) condition. Microparticles containing $80 \mathrm{mg}$ equivalent of GLZ were subjected to this study. The results obtained from dissolution studies are graphically represented in figure 4 and 5. As PCL is semi-crystalline polymer, water can penetrate easily into the amorphous part of the polymer matrix thus facilitating the release of the drug by diffusion through pores that were created during the evaporation of the solvent from the polymer matrix [29]. A wide range of release rates of the drug was obtained by simple change of the polymers ratio. An increase in polycaprolactone content of the

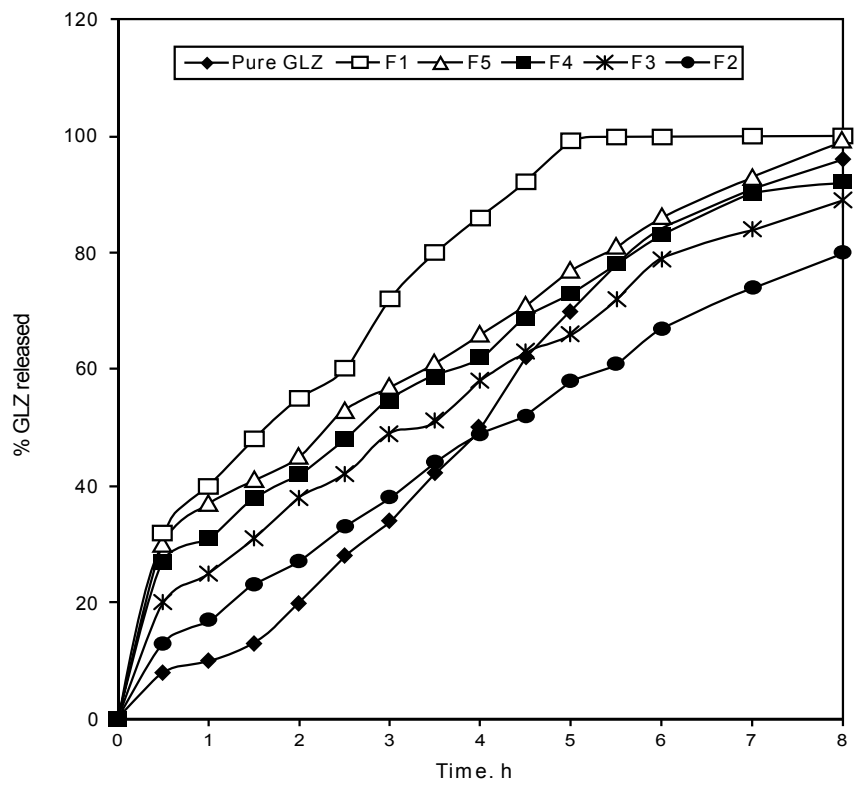

Figure 4: Release profile of GLZ from pure powdered drug and from different GLZ-loaded microparticles.

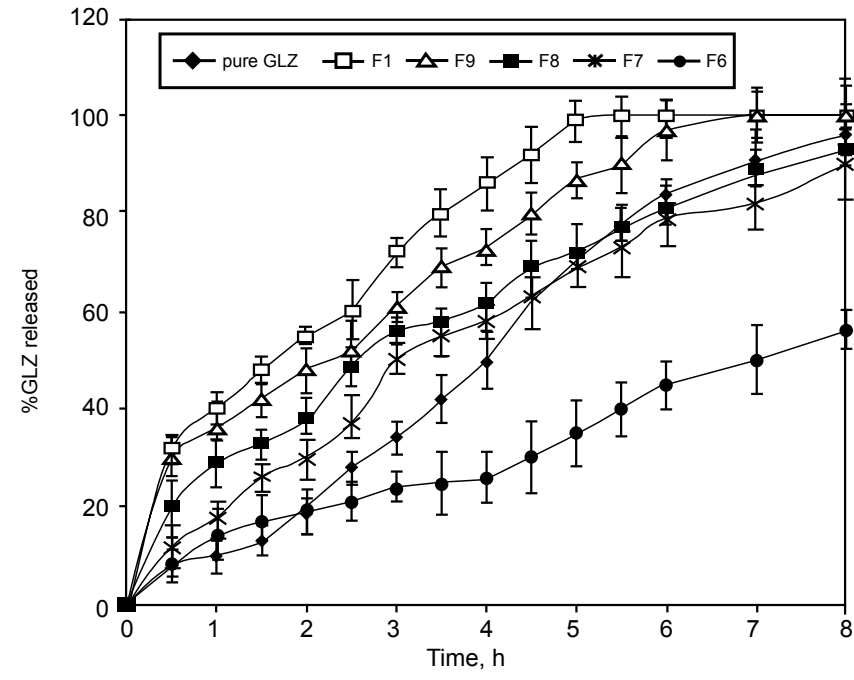

Figure 5: Release profile of GLZ from pure powdered drug and from different GLZ-loaded microparticles.

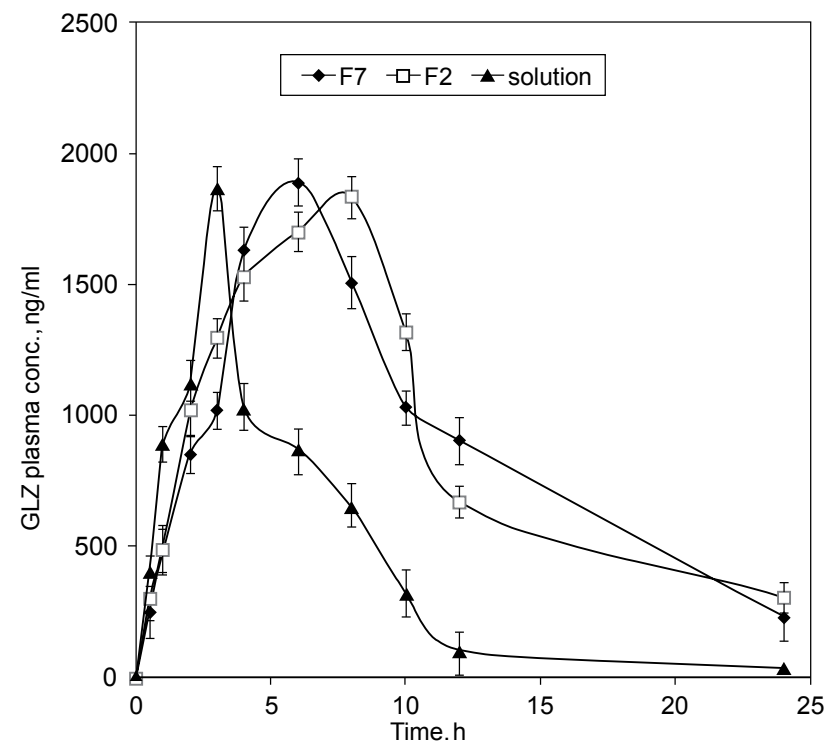

Figure 6: GLZ-plasma concentration vs time profiles after oral administration of GLZ solution and microparticles (equivalent $40 \mathrm{mg} / \mathrm{kg}$ ) to 6 rabbits.

microparticles brought about an increase in the release rate (Table 2). GLZ was totally dissolved in phosphate buffer, $\mathrm{pH} 6.8$ after $8 \mathrm{~h}$. While microparticles released different amounts of drug after 8 hours, from $100.0 \pm 3.0 \%$ (PCL/EC, 1:0), $100.0 \pm 4.3 \%$ (PCL/EC, 0.8:0.2). $93.5 \pm 4.5$ (PCL/EC, 0.8:0.2) $90.5 \pm 6.8$ (PCL/EC, 0.5:0.5) and $56.7 \pm 7.5$ (PCL/EC, 0.2:0.8). Microparticles composed of PCL/EC polymer blends showed more sustained release of GLZ at all polymer ratios than Eudragit RS - loaded microparticles. These results are in agreement with Gibaud et al. [30].

\section{Release kinetics}

Mathematical models have been used extensively for the parametric representation of dissolution data [31]. The date of release studies were subjected to kinetics models: Zero order, First order, Higuchi models as estimated in table 3. After fitting these models to the dissolution data 
Citation: Barakat NS, Al-Shazli G, Almedany AH (2012) Development of Novel Controlled Release Gliclazide-Loaded poly( $\varepsilon$-caprolactone) Microparticles: Effect of Polymer Blends. Pharm Anal Acta 3:150. doi:10.4172/2153-2435.1000150

Page 8 of 9

\begin{tabular}{|c|c|c|c|c|}
\hline Pharmacokinetic parameter & F 2 & F 7 & GLZ solution & Dunn's multiple comparison Test $P$ value \\
\hline $\mathrm{C}_{\max }(\mathrm{ng} / \mathrm{ml})$ & $1706.5 \pm 165.3$ & 1890. $1 \pm 150.2$ & $1875.6 \pm 55.3$ & $\begin{array}{c}P>0.05 \text { F2 \& F7 } \\
P>0.05 \text { F7 \& Solution } \\
P>0.05 \text { F2 \& solution }\end{array}$ \\
\hline $\mathrm{T}_{\max }(\mathrm{h})$ & $8.02 \pm 1.02$ & $6.48 \pm 0.86$ & $3.24 \pm 0.58$ & $\begin{array}{c}P>0.05 \mathrm{~F} 2 \text { \& solution } \\
P>0.01 \mathrm{~F} 7 \& \text { solution } \\
P>0.05 \mathrm{~F} 2 \& \mathrm{~F} 7\end{array}$ \\
\hline $\mathrm{AUC}_{0-24}(\mathrm{ng} / \mathrm{ml} / \mathrm{h})$ & $21741.3 \pm 696.6$ & $20464.5 \pm 1326.7$ & $8214.7 \pm 403.1$ & $\begin{array}{c}P>0.05 \text { F2 \& F7 } \\
P>0.05, \text { F2, F7 \& Solution }\end{array}$ \\
\hline$A \cup C_{0-\infty}(\mathrm{ng} / \mathrm{ml} / \mathrm{h})$ & $23135.2 \pm 1819.2$ & $21314.2 \pm 1349.1$ & $11393.6 \pm 452.6$ & $P>0.001 \mathrm{~F} 2, \mathrm{~F} 7$ \& Solution \\
\hline MRT (h) & $11.21 \pm 1.85$ & $12.83 \pm 1.32$ & $9.85 \pm 2.43$ & $P>0.05 \mathrm{~F} 2, \mathrm{~F} 7$ \& solution \\
\hline Lag time (h) & 0.86 & 0.42 & 0.00 & \\
\hline
\end{tabular}

Table 2: Mean pharmacokinetic parameters of gliclazide after oral administration of Formula F7, F2 microparticles and GLZ solution to six rabbits ( $\mathrm{n}=6$ ).

\begin{tabular}{|c|c|c|c|c|c|c|c|c|c|c|}
\hline \multirow{2}{*}{ Formula code } & \multicolumn{2}{|c|}{ Zero order } & \multicolumn{2}{|c|}{ First order } & \multicolumn{2}{|c|}{ Higuchi } & \multicolumn{2}{|c|}{ Korsmeyer-Peppas } & \multirow[t]{2}{*}{$\%$ burst release after 1 hour \pm SD } & \multirow{2}{*}{$\begin{array}{l}\mathrm{T}_{50 \%} \\
(\mathrm{~h})\end{array}$} \\
\hline & r & $\mathrm{k}_{0}$ & r & $\mathrm{k}_{1}$ & r & $\mathrm{k}_{\mathrm{H}}$ & $r$ & $n$ & & \\
\hline $\mathrm{F} 1$ & 0.920 & 11.795 & -0.890 & -0.302 & 0.944 & 39.155 & 0.989 & 0.491 & $40 \pm 1.43$ & 2.5 \\
\hline $\mathrm{F} 2$ & 0.994 & 9.721 & -0.991 & -0.083 & 0.983 & 29.925 & 0.993 & 0.803 & $17 \pm 2.76$ & 4.5 \\
\hline F3 & 0.982 & 10.385 & -0.984 & -0.111 & 0.992 & 32.616 & 0.990 & 0.593 & $25 \pm 2.80$ & 3.5 \\
\hline $\mathrm{F} 4$ & 0.972 & 10.440 & -0.983 & -0.130 & 0.994 & 33.238 & 0.982 & 0.508 & $31 \pm 3.62$ & 3.0 \\
\hline F5 & 0.969 & 10.748 & -0.904 & -0.188 & 0.993 & 34.179 & 0.979 & 0.455 & $37 \pm 1.78$ & 3.0 \\
\hline F6 & 0.988 & 6.405 & -0.984 & -0.040 & 0.964 & 19.377 & 0.989 & 0.673 & $12 \pm 3.82$ & 3.5 \\
\hline $\mathrm{F} 7$ & 0.988 & 11.368 & -0.986 & -0.118 & 0.982 & 35.116 & 0.997 & 0.797 & $18 \pm 2.98$ & 7.0 \\
\hline F8 & 0.977 & 10.841 & -0.984 & -0.131 & 0.994 & 34.299 & 0.996 & 0.582 & $29 \pm 3.89$ & 3.0 \\
\hline F9 & 0.962 & 11.769 & -0.934 & -0.200 & 0.992 & 37.796 & 0.985 & 0.502 & $36 \pm 4.20$ & 2.5 \\
\hline Pure GLZ & 0.989 & 13.439 & -0.947 & -0.165 & 0.944 & 39.858 & 0.982 & 1.052 & - & 4.0 \\
\hline
\end{tabular}

Table 3: Correlation coefficient and $T_{50 \%}$, calculated from the release data of GLZ-loaded Polycaprolactone microparticles after fitting the whole release profile of GLZ from various microparticles into different mathematical models $(n=3)$

of formulations the selection was based on the comparison of higher determination coefficient (Table 3). To determine the mechanism of drug release, the initial portion (i.e., $M_{t} / M_{\infty} 60 \%$ ) of $\%$ drug release vs. time profiles have been fitted to the empirical equation proposed by Ritger and Peppas [32]: $\mathrm{M}_{\mathrm{t}} / \mathrm{M}_{\infty}=\mathrm{Kt}^{\mathrm{n}}$

where $M_{t} / M_{\infty}$ is the fraction of drug released at time $t, K$ is a kinetic rate constant and $n$ is diffusional exponent characterizing the mechanism of drug release. If $n=0.5$, drug diffuses and releases from the polymer matrix following a Fickian diffusion. For $n>0.5$, anomalous or nonFickian type diffusion occurs. If $n=0.8-1.0$, case II release kinetics is prevalent. Estimated values of $n$ along with the correlation coefficient, $r$ values are presented in table 3. Ha et al. [33] have shown that the degradation of PCL was very slow in an aqueous medium because of its semi-crystallinity and hydrophobicity. This indicates that drug release was a result of diffusion and not of the degradation of the polymer. Formulation F1, F4, F5, and F9 showed Fickian release mechanism, $n=$ 0.5, while the formulations F3, F6, F8 showed non-Fickian (anomalous) release. The release of GLZ from formulation F2 and F7 was shifted towards zero order type of release.

\section{In vivo studies}

Analysis of GLZ using HPLC was validated. The assay was linear $\left(r^{2}=0.9996\right)$ in the concentration range $100-5000 \mathrm{ng} \mathrm{mL} \mathrm{m}^{-1}$. The method was validated with respect to accuracy and inter- and intra-day precision as per ICH guidelines. The validation studies showed overall intra- and inter-day variations (RSD) of less than $4.1 \%$ and $9.2 \%$, respectively. The percentage difference between amounts determined and spiked was considered to be a measure of accuracy. An accuracy of $98.7-112.0 \%$ was obtained for each of the analytes tested, and RSD was $<9.8 \%$.
There was a significant change in serum gliclazide levels and an alteration in pharmacokinetic parameters like $\mathrm{C}_{\max }, \mathrm{T}_{\max }, \mathrm{AUC}_{0-24}$, $\mathrm{AUC}_{0-\infty}$, of gliclazide profile from GLZ solution and Formulation F2, F7. The mean pharmacokinetic parameters are summarized in table 2. The pharmacokinetic methods used were standard noncompartmental analysis and linear trapezoidal rule for AUC calculations and the mean plasma GLZ concentration vs time profiles are presented in figure 6 . When pure GLZ solution was administered, a rapid reduction in serum GLZ level was observed within $3 \mathrm{~h}$ after oral administration. In the case of GLZ-loaded microparticles F2, F7 the reduction of serum GLZ levels was slow and reached maximum within 8 and 6 hours, respectively after oral administration of F2 and F7. The serum GLZ level was sustained over longer periods of time due to the slow release and absorption of GLZ over longer period of time.

\section{Conclusion}

Gliclazide loaded microparticles were successfully prepared by solvent evaporation method using Polycaprolactone and Eudragit $\mathrm{RS} /$ or ethyl cellulose polymeric blends. It is established that the drug dissolution profile could be slowed down by increasing the retardant polymer amount in the formulations. The GLZ plasma concentration for PCL-Eudragit RS or ethyl cellulose microparticles was generally higher than that observed for GLZ solution after oral administration and extended for longer time. The incorporation of GLZ into polymeric PCL microparticles had been achieved as a way of increasing its oral bioavailability and to improve its therapeutic effectiveness.

\section{Acknowledgements}

The authors extend their appreciation to the Deanship of Scientific research at King Saud University for funding the work through the research group (RGP VPP-039). 
Citation: Barakat NS, Al-Shazli G, Almedany AH (2012) Development of Novel Controlled Release Gliclazide-Loaded poly( $\varepsilon$-caprolactone) Microparticles: Effect of Polymer Blends. Pharm Anal Acta 3:150. doi:10.4172/2153-2435.1000150

\section{References}

1. Swarbick J (2007) Encyclopedia of Pharmaceutical Technology. Marce Dekker, New York 2: 61-88.

2. Chasin M, Langer RS (1990) Biodegradable polymers as drug delivery systems. Marcell Dekker Inc, New York.

3. Zatuchni GI (1984) Long-acting contracetive delivery systems. Philadelphia.

4. Baras B, Benoit MA, Gillard J (2000) Influence of various technological parameters on the preparation of spray-dried poly(1-caprolactone) microparticles containing a model antigen. J Microencapsul 17: 485-498.

5. Benoit MA, Baras B, Gillard J (1999) Preparation and characterization of protein-loaded poly(epsilon-caprolactone) microparticles for oral vaccine delivery. Int J Pharm 184: 73-84.

6. Giunchedi P, Conti B, Maggi L, Conte U (1994) Cellulose acetate butyrate and polycaprolactone for ketoprofen spray-dried microsphere preparation. $J$ Microencapsul 11: 381-393.

7. Buntner B, Nowak M, Kasperczyk J, Riba M, Grieb P, et al. (1998) The application of microspheres from the copolymers of lactide and epsilon-caprolactone to the controlled release of steroids. J Control Release 56: 159-167.

8. Das GS, Rao GH, Wilson RF, Chandy T (2000) Colchicine encapsulation within poly(ethylene glycol)-coated poly(lactic acid)/poly(epsilon- caprolactone) microspheres-controlled release studies. Drug Deliv 7: 129-138.

9. Shen Y, Sun W, Zhu K, Shen Z (2000) Regulation of biodegradability and drug release behavior of aliphatic polyesters by blending. J Biomed Mater Res 50 : 528-535.

10. Paul DR (1978) Polymer Blends. Academic Press, New York 2: 369-389.

11. Lin WJ, Flanagan DR, Linchardt RJ (1999) A novel fabrication of poly ( $\varepsilon$-caprolactone) microspheres from blends of poly ( $\varepsilon$-caprolactone) and poly(ethylene glycol)s. Polymer 40: 1731-1735.

12. Nihant N, Schugens Ch, Grandfils C, Jérôme R, Teyssié P, et al. (1994) Polylactide microparticles prepared by double emulsion/evaporation technique. I. Effect of primary emulsion stability. Pharm Res 11: 1479-1484.

13. Schernthaner G (2003) Gliclazide modified release: a critical review of pharmacodynamic, metabolic, and vasoprotective effects. Metabolism 52: 29-34.

14. Campbell DB, Lavielle R, Nathan C (1991) The mode of action and clinical pharmacology of gliclazide: a review. Diabetes Res Clin Pract 14: S21-S36.

15. Barakat NS, Almurshedi AS (2011) Preparation and Characterization of Chitosan Microparticles for oral Sustained Delivery of Gliclazide: in vitro/in vivo evalution. Drug Dev Res 72: 235-246.

16. Liggins RT, D’Amours S, Demetrick JS, Machan LS, Burt HM (2000) Paclitaxe loaded poly(L-lactic acid) microspheres for the prevention of intraperitoneal carcinomatosis after a surgical repair and tumor cell spill. Biomaterials 21 : 1959-1969.

17. Hombreiro Perez MH, Zinutti C, Lamprecht A, Ubrich N, Astier A, et al. (2000) The preparation and evaluation of poly(epsilon-caprolactone) microparticles containing both a lipophillic and a hydrophilic drug. J Control Release 65 429-438.

18. Junyapraset VB, Pornsuwannapha S (2008) Floating properties and releas characteristics of hollow microspheres of acyclovir. Drug Deliv 15: 331-341.

19. Ahuja N, Katare OP, Singh B (2007) Studies on dissolution enhancement and mathematical modeling of drug release of a poorly water-soluble drug using water-soluble carriers. Eur J Pharm Biopharm 65: 26-38.

20. Kumar KE, Ramesh A, Yadav RS, Satyanarayana S (2007) Determination of gliclazide in rabbit serum by RP-HPLC. Acta Ciencia Indica Chemistry 33 273-278.

21. Guidance for Industry-Q2B Validation of Analytical Procedures: Methodology (1996) European Agency for the Evaluation of medicinal Products (ICH) Londres.

22. Raffin RP, Colomẽ LM, Guterres SS, Pohlmann AR (2007) Enteric controlled release pantoprazole-loaded microparticles prepared by Eudragit S100 and poly(epsilon-caprolactone) blend. Pharm Dev Technol 12: 463-471.

23. Comoglu T, Gonul N, Dogan A, Basci N (2008) Development and in vitro evaluation of pantoprazole-loaded microspheres. Drug Deliv 15: 295-302.

24. Sengel T, Hascicek C, Gönúl N (2006) Development and in vitro evaluation of modified release tablets including ethyl cellulose microspheres loaded with dilitiazem hydrochloride. J Microencapsul 23: 135-152.

25. Tewa-Tagne P, Briancon S, Fessi H (2007) Preparation of redispersible dry nanocapsules by means of spray drying: development and characterisation. Eur J Pharm Sci 30: 124-135.

26. Kim CK, Kim MJ, Oh KH (1994) Preparation and evaluation of sustained release microspheres of terbutaline sulfate. Int J Pharm 106: 213-219.

27. Nalva HS (1997) Spectroscopy and physical properties. New York: John Wiley \& Sons Ltd.

28. Rosca ID, Watari F, Uo M (2004) Microparticle formation and its mechanism in single and double emulsion solvent evaporation. J Control Release 99: 271

29. Das SK, Das NG (1998) Preparation and in vitro dissolution profile of dual polymer (Eudragit RS100 and RL100) microparticles of diltiazem hydrochloride. J Microencapsul 15: 445-452.

30. Gibaud S, Jabir Al Awwadi N, Ducki C, Astier A (2004) Poly (epsiloncaprolactone) and Eudragit microparticles containing fludrocortisone acetate. Int J Pharm 269: 491-508.

31. Yüksel N, Kanik AE, Baykara T (2000) Comparison of in vitro dissolution profiles by ANOVA-based model dependent and independent methods. Int $J$ Pharm 209: 57-67.

32. Ritger PL, Peppas NA (1987) A simple equation for description of solute release II: Fickian and anomalous release from swellable devices. J Control Release 5: 37-42.

33. Ha JH, Kim SH, Han SY (1997) Albumin release from bioerodible hydrogels based on semi-interpenetrating polymer networks composed of poly(ecaprolactone) and poly- (ethylene glycol) macromer. J Control Release 49: 253-262. 